\title{
Note on morphology of two nematode species Ascaridia hermaphrodita and Ascaridia platyceri (Nematoda): scanning electron microscope study
}

\author{
I. HODOVÁ ${ }^{1}$, V. BARUŠ $\check{2}^{2}$ V. TUKAČ $\check{C}^{3}$
}

\begin{abstract}
${ }^{1}$ Department of Botany and Zoology, Faculty of Science, Masaryk University, Kotlářská 2, 61137 Brno, Czech Republic, E-mail: hodova@sci.muni.cz; ${ }^{2}$ Institute of Parasitology, Biology Centre, Academy of Sciences of the Czech Republic, Branišovská 31, 37005 České Budějovice, Czech Republic; ${ }^{3}$ Clinic of Avian, Reptiles and Small Mammals Diseases, University of Veterinary and Pharmaceutical Sciences Brno, Palackého 1/3, 61242 Brno, Czech Republic
\end{abstract}

\begin{abstract}
Summary
Morphological features of adult specimens of Ascaridia hermaphrodita and A. platyceri (Nematoda: Ascaridida), parasitizing parrots (Psittaciformes), were studied for the first time using scanning electron microscopy. The morphology of A. hermaphrodita, the type species of Ascaridia, coincides fully with the generic diagnosis. The shape of the labial inner structure (two spoon-like projections), cervical alae and spicule with cuticular wings were typical for this species. A. hermaphrodita has been found in the Czech Republic for the first time in a new host, Amazona pretrei, from Brazil. The morphology of Ascaridia platyceri does not correspond with the generic diagnosis in all aspects, as some variation was found, mainly in the presence of interlabia, small teeth in the inner ribbon of the lips and long lateral alae. These morphological characteristics in other species of Ascaridia are discussed. The generic diagnosis is to include the statement "interlabia very rarely present".
\end{abstract}

Key words: Ascaridia hermaphrodita; A. platyceri; Psittaciformes; Czech Republic; morphology; differences

\section{Introduction}

Nematodes of the genus Ascaridia (Dujardin, 1845) infect many species of birds (Mozgovoj 1953, 1973; Yamaguti 1961). To date, only five species of ascaridiids have been recorded from parrots (Psittaciformes). Two species, $A$. platyceri Hartwich et Tscherner, $1979(=A$. sprenti Mines, 1979), and A. hermaphrodita (Froelich, 1789), are the species most commonly found in Europe (Hartwich \& Tscherner, 1979; Kajerová et al., 2004a) in parrots living in captivity.

A. platyceri in the Czech Republic was first reported by Kajerová et al. (2004b). In the present study, we report the first record of $A$. hermaphrodita in the Czech Republic.
The SEM study provides more details of the morphology of adult specimens of both species with new differentiation features.

\section{Material and Methods}

An infection with parasites showing the morphological characteristics of ascaridiid nematodes was observed in the small intestine of two species of parrots during a postmortem examination:

1. Psittacula longicauda (Boddaert, 1783) imported in spring 2005 to Austria from the Philippines and then in summer 2005 transported to the Czech Republic. The parrot died after 1 week in captivity, due to heavy infection with ascaridiids (A. platyceri); in total, 242 specimens were found.

2. Amazona pretrei (Temminck, 1830) imported to the Czech Republic in 2005 from Brazil. Died after 3 months in captivity with symptoms of ascaridiosis. 37 nematodes, Ascaridia hermaphrodita (36 adults -7 males and 29 females, 1 fourth-stage larva), were detected in the small intestine.

Specimens were fixed in $4 \%$ formaldehyde solution and cleared in glycerine-water for morphological examination. A light microscope Olympus BX 50 equipped with a differential interference contrast (Nomarski DIC) and digital image analysis (analySIS) for measuring was used. Nematodes were identified to species according to Travassos (1913, 1930), Hartwich and Tscherner (1979), and Kajerová et al. (2004b).

Specimens used for scanning electron microscopy ( 5 males and 5 females of both species) were washed several times in water, fixed with hot $4 \%$ formaldehyde and stored at room temperature. Prior to analysis, they were dehydrated through ethanol, dried in a CPD 030 critical point drying apparatus (Bal-tec, Balzers, Liechtenstein) using liquid 
$\mathrm{CO}_{2}$, mounted on aluminium stubs with double sided adhesive discs, coated with gold in a SCD 040 sputter coating unit (OC Oerlikon Balzers Coating, Balzers, Liechtenstein) and examined in a VEGA scanning electron microscope operating at $20 \mathrm{kV}$.

Reference material of $A$. hermaphrodita has been deposited in the collection of the Institute of Parasitology, Academy of Sciences of the Czech Republic, České Budějovice, Czech Republic, No. N-508.

\section{Results}

\section{Selected morphological characteristics}

\section{Ascaridia hermaphrodita (Plate 1)}

Mouth opening surrounded by one dorsal and two lateroventral lips $(180-231 \mu \mathrm{m}$ wide and $147-179 \mu \mathrm{m}$ high), each of them divided into one medial and two lateral lobes (Fig. 1). One pair of eliptical papillae, width $32-38$, is symmetrically situated in middle of dorsal lip (Fig. 2). One flat elliptical papilla situated near ventral margin of lateroventral lips and one round papilla with amphideal opening located near lateral margin of lip (Fig. 1). In addition to these papillae, a group (three to four) of small rounded papillae is present on lateroventral lips. Viewed from the lateral or dorsal surfaces, the margins of medial lobes are rounded, their top margins separated by a transverse shallow cut. Top margins of medial lobes overlap a laterally flat rounded projection (in length $3-5$ and width 16 - 22). The surface between lips is smooth, without interlabia. Top margin and inner wall of medial lobes smooth. Two spoon-like flat elements (height $40-55$ and width $18-25$ ) extend from every lip, approximately from mid-point of inner wall of medial lobes (Fig. 3). The lateral alae reach maximum width 100 , starting just below base of lips $(80-92)$ and ending in first third of body length, above vaginal opening (Fig. 4). Cuticula in precloacal and post-cloacal regions of ventral surface of male is without marked structures (almost smooth), forming a slight bulge on body (Fig. 5). Two spicules of same morphology and shape are formed by lower sclerotising reinforcement, to which cuticular wings (high 30 - 45) forming a smooth channel (Fig. 6). Viewed laterally, wing as appears to be unilateral. Wings end $42-51$ from distal rounded tip of spicule (Fig.7).

\section{Ascaridia platyceri (Plate 2)}

Mouth bordered by one dorsal and two lateroventral lips ( 84 - 137 wide and $84-120$ high), each of them divided into one medial and two lateral lobes. Triangular interlabia do not exceed half height of lips (Fig. 8). Anterior edge of medial lobe forms narrow rounded ribbon separated from lip by shallow transverse slit. Two oval papillae (wide $8-$ 14) are present on dorsal lip in middle of its height, separated by slit in cuticule of lip. One flat elliptical papilla present near ventral margin and one small rounded papilla with amphideal opening located near lateral margin of lateroventral lips. In addition, group of three small rounded papillae (accessory labial papillae), distributed in line or in triangle, is present (Fig. 9, 10). Inner wall of medial lobe of lips formed by flat reinforcement separated by shallow slit from external wall of lip. Anterior margin of reinforcement has one line of 27 - 29 small teeth (height $1-$ 2), in length of edge $49-70$ (Fig. 11). Lateral alae (maximum width 20) decreased in cervical region and melt into low transverse tegumentary ridges to level of anus (Figs 12 and 13). Cuticle in pre-cloacal and post-cloacal regions of male has fine transverse serrations, without marked bulge (Fig. 14). Spicules without cuticular wings. Distal tip of spicules rounded.

\section{Discussion}

The genus Ascaridia (Dujardin, 1845) has a cosmopolitan distribution and incorporates more than 55 species in the intestine of mainly terrestrial birds (Mozgovoj, 1953, 1973; Yamaguti, 1961). Seven Ascaridia species have been found in birds of the order Psittaciformes. Two species have been detected most frequently in wild and captive parrots (survey in Kajerová et al., 2004b). A. platyceri was found in the Czech Republic for the first time by Kajerová et al. (2004b).

In the present study, $A$. hermaphrodita is reported for the first time from a new host, Amazona pretrei, imported from Brazil. Ascaridia hermaphrodita is the type species of the genus and its morphological features reflect all the characters of the generic diagnosis (Mozgovoj, 1953; Yamaguti, 1961) as follows: Ascaridiinae with cuticular lateral flanges generally present; lips without interlabia; oesophagus club-shaped, without posterior bulb. Male: precloacal sucker with chitinous rim; caudal alae narrow, papillae relativelly large; spicules equal or subequal; gubernaculum absent. Female: uteri opposed; vulva near middle of the body; oviparous; eggs thick shelled.

The morphology of the lips with inner spoon-like projections is a typical morphological feature of $A$. hermaphrodita recognized using SEM. This feature was described and documented by Travassos (1930). The morphology of the spicules was previously studied by Skrjabin (1917) but he did not mention the presence of two longitudinal cuticular alae, forming a channel for the purpose of directing the sperm, as suggested in the present study. The shape of the lips and the labial papillae and the absence of interlabia correspond with the diagnosis of the genus.

Hartwich and Tscherner (1979) and Mines (1979) noted discrepancies with the generic diagnosis in the original description of $A$. platyceri. It concerns the presence of the triangular interlabia having blunt tips and not exceeding one half of the height of the lips. This feature was documented also by Kajerová et al. (2004a) and by SEM in the present study.

In the lower part of the lateroventral lips, three small accessory papillae were observed for the first time for both $A$. hermaphrodita and $A$. platyceri. In our opinion, these 
are sense organs - mechanoreceptors already described from other Ascaridida species (McLaren, 1976; Wright, 1980).

Another structure of taxonomic importance is a flat reinforcement on the inner wall of the medial lobe of the lips that is equipped with a line of small teeth at the edge. This structure is not mentioned in the generic diagnosis and it is most likely a rare feature in the genus. Among the members of Ascaridia, it is present only in a few species. The presence of large and finger-like interlabia and line of small teeth on the inner margin of the lips has been observed in A. australis (Linstow, 1879), from the host Macropygia nigrirostris (Columbiformes, Columbidae) common in New Guinea and NW Islands. Mozgovoj (1953) noted that presence of the interlabia in this species does not correspond with the diagnosis of the genus. Unlike Yamaguti (1961), he also mentioned the birds Aviceda subcristata bismarckii (Accipitridae, Falconiformes) from New Britain, New Ireland and New Hanover and Ninox odiosa (Strigiformes, Strigidae) from New Britain as the hosts of Ascaridia australis. However, we believed that these two host records need verification.

Lips with a dentate-like wall were described in Ascaridia compressa (Schneider, 1866) from Gallus gallus f. domestica, in North Australia. Also, Skrjabin (1920) described the lips as having a toothlike wall on the upper margin. A flexure with small teeth in the middle of the outer margin is absent on the lateroventral lips; the front margin of flexure with teeth comes immediately to the margin of the own lip. In an illustration by Schneider (1866), the tooth-
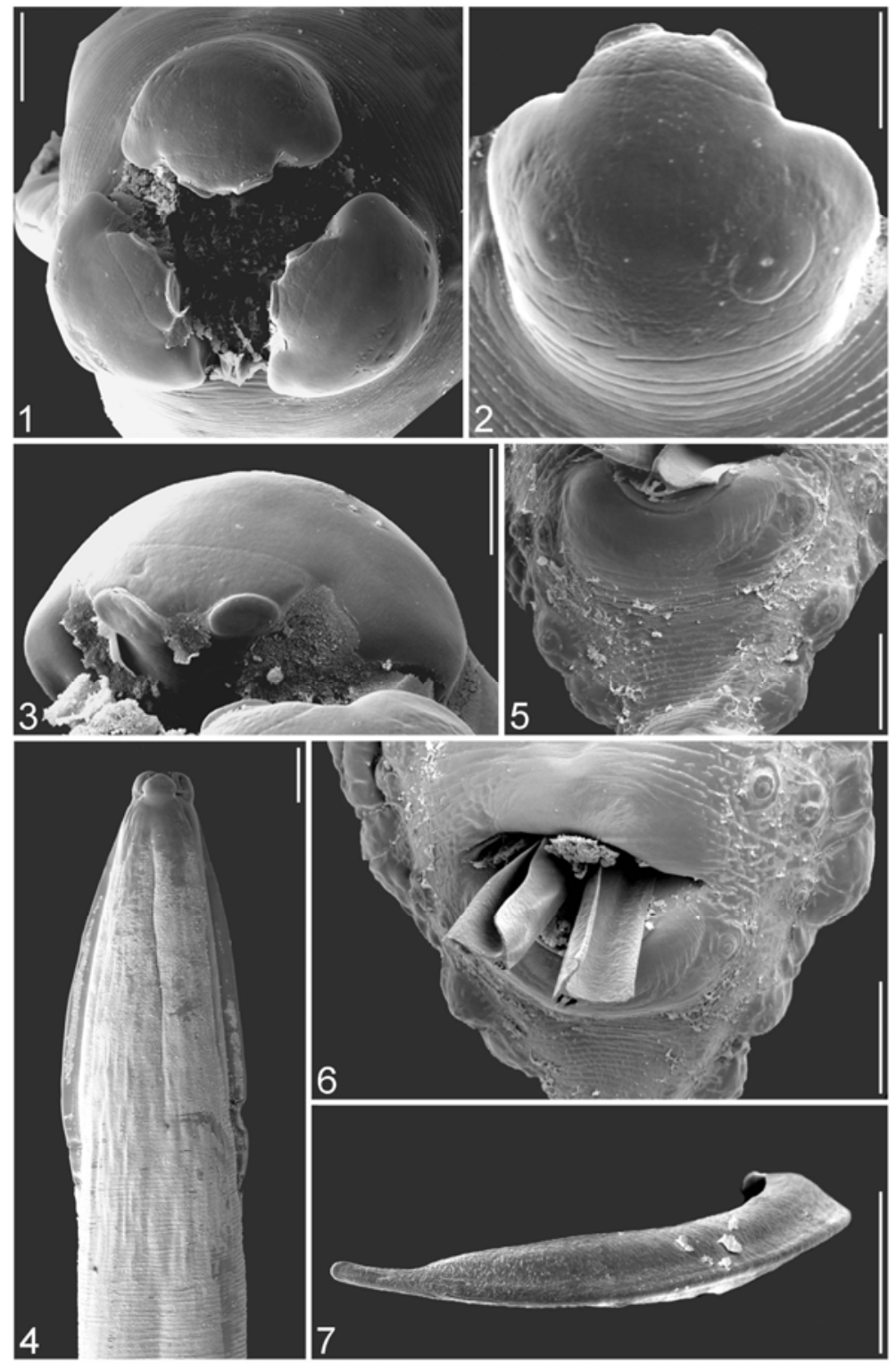

Plate 1. Ascaridia hermaphrodita - scanning electron micrographs. Fig. 1. Head (apical view); Fig. 2. Dorsal lip (total view); Fig. 3. Two inner finger-like elements in the medial lobe of the lateroventral lip; Fig. 4. Anterior extremity (dorsal view); Fig. 5. Postcloacal region of male (ventral view); Fig. 6. Spicule with two alae (ventral view); Fig. 7. Distal end of the spicule (lateral view); (Scale - bars: Fig. $2=40 \mu \mathrm{m}$; Fig. 1, $3=50 \mu \mathrm{m}$; Fig. 5, $7=100 \mu \mathrm{m}$; Fig. 4,6=200 $\mu \mathrm{m}$ ). 

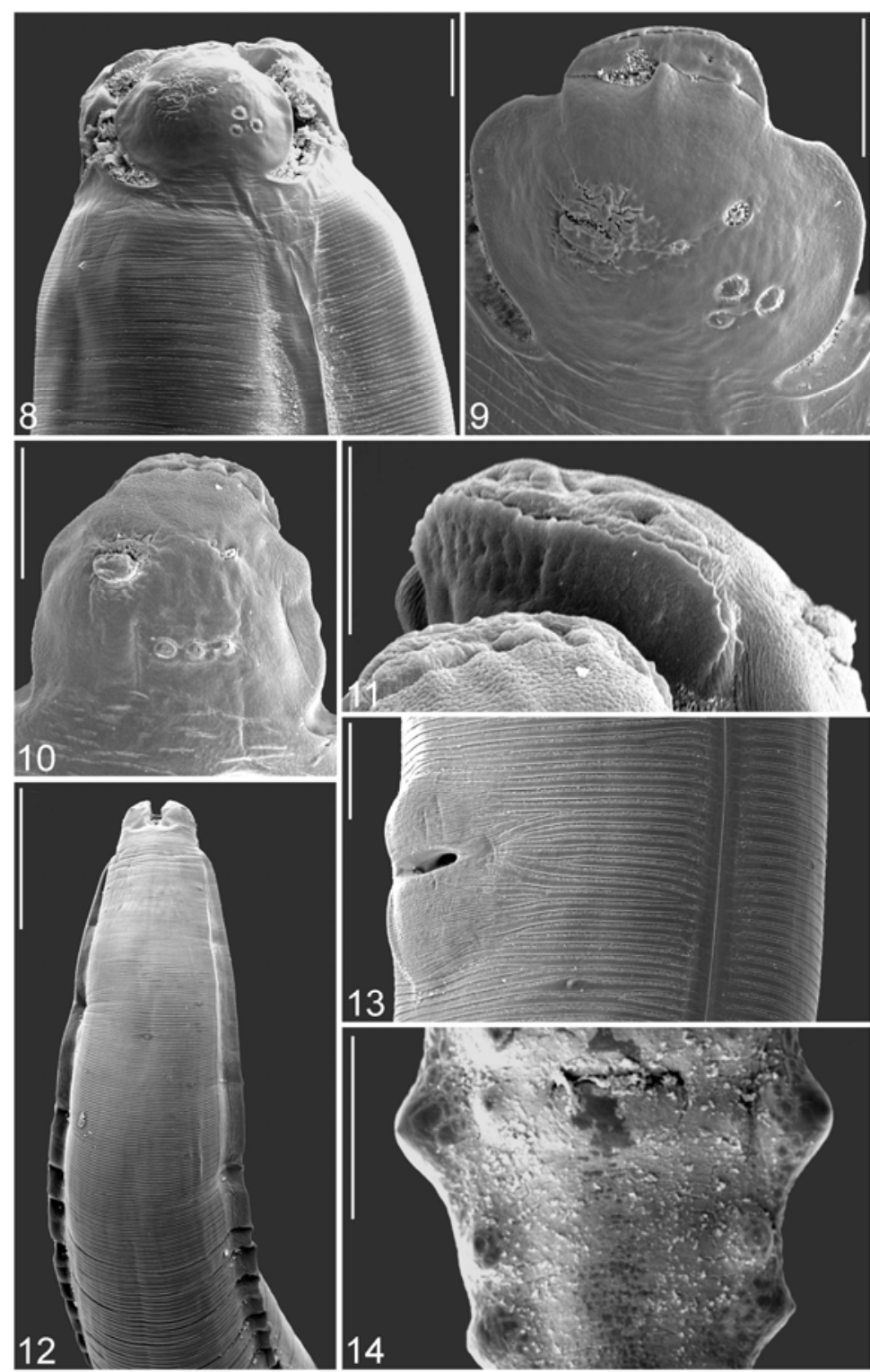

Plate 2. Ascaridia platyceri - scanning electron micrographs. Fig. 8. Head (lateroventral view) with interlabia; Fig. 9, Fig. 10. Lateroventral lip (total view); Fig. 11. Flat reinforcement of the medial lobe of lip with small teeth (detail); Fig. 12. Anterior extremity (ventral view);

Fig. 13. Lateral ala at vulvar region (lateral view); Fig. 14. Postcloacal region of male (ventral view); (Scale-bars: Fig. $11=20 \mu \mathrm{m}$; Fig. $10=30 \mu \mathrm{m}$; Fig. $9=40 \mu \mathrm{m}$; Fig. $8=50 \mu \mathrm{m}$; Fig. 13, $14=100 \mu \mathrm{m}$; Fig. $12=200 \mu \mathrm{m})$.

like ribbon of the lip overlaps only the upper and lateral parts of the medial lobe, which, however, corresponds with the description of $A$. platyceri rather than A. compressa. Therefore, it is impossible to consider $A$. compressa as a species conspecific with $A$. galli (Schrank, 1788) as suggested by Frenzen (1955).

Also in the description of $A$. serrata (Schneider, 1866) from Penelope humeralis and Pipile jacutinga (Cracidae, Galliformes) in Brazil, the presence of anterior and posterior tooth lamellae is mentioned. One row of eight small teeth is present in the form of tooth lamellae. In a redescription of $A$. francolina (Linstow, 1899) from Pternistis bicalcaratus (Phasianidae, Galliformes) from Africa, Khalil (1932) described the presence of three tooth-like combs on the inner surface of the lips. Gushanskaya (1950) also mentioned fine small teeth on the margins of the lips 112 in Ascaridia sp. from Tetrastes bonasia viciniatus (Galliformes, Tetraonidae) from Sakhalin Island (Russia).

Lateral alae on the spicules of $A$. platyceri were not observed by Hartwich and Tscherner (1979), Mines (1979) or Kajerová et al. (2004b). The presence of the interlabia and small teeth on the inner wall of the lips does not correspond to the generic diagnosis of Ascaridia (as given by Mozgovoj, 1953, 1973 and Yamaguti, 1961).

The occurrence of two spoon-like flat elements on the inner wall of the medial lobes of the lips, which we observed in A. hermaphrodita, is rare in Ascaridia. This feature was reported in the original description and illustration of A. cristata by Linstow (1901) from Balearica pavonina and B. regulorum (Gruidae, Gruiformes) from Africa (Kongo). Also, Kreis (1938) mentioned the presence of three toothlike plates on every lip in Ascaridia sp. from 
Gallus sp. (locality unlisted).

The presence or absence of cuticular bosses in the cloacal region of the males is one of the main features used for the differentiation of species by Mozgovoj (1953, 1973) and Freitas and Ibanez (1965). In both species studied here, the cuticle is only finely transversely striated (in A. platyceri it is more strikingly marked, but the striation in $A$. hermaphrodita is finer). Therefore, it markedly differs from ascaridiids with cloacal regions ornamented with thickened cuticular bosses. This feature, typical for A. galli, was emphasized by Baruš (1966) and Baruš et al. (1975) in numerous other species of Ascaridia (see Mozgovoj, 1953, 1973; Freitas \& Ibanez, 1965).

$A$. hermaphrodita and $A$. platyceri belong to the large group of species of Ascaridia with lateral cuticular alae; in the case of $A$. platyceri, they end near the anus. The morphological features of $A$. hermaphrodita documented in the present study fully correspond with the diagnosis of $\mathrm{As}$ caridia. In the case of $A$. platyceri, only the presence of the interlabia does not correspond with the generic diagnosis. As an appropriate resolution, we amendation the generic diagnosis to include the statement: "in the genus Ascaridia, interlabia are very rarely present".

\section{Acknowledgements}

This study was supported by Research Project of the Masaryk University No. MSM 0021622416. The authors would like to thank Iveta Douglas for editing the English manuscript.

\section{References}

BARUŠ, V. (1966): Some remarks on nematodes of the genus Ascaridia Dujardin, 1845 from birds in Czechoslovakia. Folia Parasit., 13: 170 - 181

BARUŠ V., RYŠAvÝ B., DANIEL M. (1975): Some cestodes and nematodes parasitizing gallinaceous and columbiform birds in Nepal. Folia Parasit., 22: 327 - 335

FreitAs DE J. F. T., IBANEZ N. (1965): Fauna helminthologica do Peru - nova especie do genero Ascaridia Durjardin, 1845 (Nematoda, Ascaridoidea). Mem. I. Oswaldo Cruz, 63: 51 - 58

FRENZEN, K. (1955): Beitrag zur Morphologie und Synonymie von Ascaridia galli Schrank 1788. Z. Parasitenk. 17: 93 - 105

GuSHANSKAJA, L. CH. (1950): About the helminthofauna of tetraonids (Tetraonidae) in Ural, Far East and Sakhalin. Trudy Vses. in-ta gelmintologii im. akad. K. I. Skrjabina, 4: 93 - 98 (in Russian)

HARTWICH G., TSCHERNER W. (1979): Ascaridia platyceri n. sp. Eine neue Spulwurmart aus Papageien. Angew. Parasitol., 20: $63-67$

KAJEROVÁ V., BARUŠ V., LITERÁK I. (2004a): Nematode from the genus Ascaridia parasitizing psittaciform birds: a review and determination key. Vet. Med. - Czech, 49: 217 $-223$

KAJEROVÁ V., BARUŠ V., LITERÁK I. (2004b): New records of Ascaridia platyceri in parrots. Vet. Med. - Czech, 49: $237-241$

KhaliL, M. B. (1932): Parasites from Liberia and French Guinea. First part. Nematoda. Z. Parasitenk., 4: 431 - 458

KREIS, H. A. (1938): Beiträge zur Kenntniss parasitescher Nematoden. VI. Parasitische Nematoden aus dem Zoologischen Garten in Basel. Zentralbl. Bakter. Parasit. Abt. 1, 141: $279-304$

Linstow, O. (1879): Helminthologische Studien. Arch. Naturgesch. Berlin, 45: 165 - 188

Linstow, O. (1901): Helminthen von den Ufern des Nyassa - Sees, ein Beitrag zur Helminthen - Fauna von Süd - Afrika. Jenaische Zeitschrift für Naturwissensch., 35: $409-428$

MCLAREN, D. J. (1976): Nematode sense organs. In DAwES, B. (Ed): Advances in parasitology, Vol. 14. Academic Press, New York, pp. 195 - 265

Mines J. J. (1979): Ascaridia sprenti, a new species of nematode in Australian parrots. Int. J. Parasitol., 9: 371 379

Mozgovou A. A. (1953): Principles of Nematodology, Vol. 2. Publ. House AN SSSR, Moscow. 352 pp. (in Russian)

Mozgovou A. A. (1973): Principles of Nematodology, Vol. 23. Publ. House AN SSSR, Moscow. 248 pp. (in Russian)

SCHNEIDER, A. (1866): Monographie der Nematoden. Berlin 357 pp. +28 plts.

SKRJABIN, K. I. (1917): Sur quelques nematodes des oiseaux de la Russia. Parasitology, 9: 460 - 481

SKRJABIN, K. I. (1920): Nematoda of domestic fowl (monographic study). Izv. Don. Vet. in-ta, Vol. 1, 2: $1-82$ (in Russian)

TRAVASSOS L. (1913): Sobre as especies brazileiras da subfamilia Heterakinae Railliet \& Henry. Trabalho Inst. Osw. Cruz, $1-33$

Travassos L. (1930): Fauna helminthologica dos "Psittacidae" do Brasil. Arch. Inst. Biol., 3: 5 - 20

YAMAGUTI S. (1961): Systema Helminthum. 3. The nematodes of vertebrates. Intersci. Publ., New York and London. $1261 \mathrm{pp}$.

Wright, K. A. (1980): Nematode sense organs. In ZUCKERMAN, B. M. (Ed): Nematodes as biological models, Vol. 2. Academic Press, New York, pp. 237 - 295 